Landscape Ecology

Original research

\title{
How does a transforming landscape influence bird breeding success?
}

Sachiko Okada ${ }^{*}$, David B. Lindenmayer ${ }^{1,2}$, Jeff T. Wood ${ }^{1}$, Mason J. Crane ${ }^{1}$, and Jennifer C.

Pierson $^{1}$

${ }^{1}$ S. Okada, J. Wood, M.J. Crane, J.C. Pierson

Fenner School of Environment and Society,

The Australian National University,

141 Linnaeus Way,

Canberra, ACT 2601, Australia

${ }^{2}$ Fenner School of Environment and Society,

Long Term Ecological Research Network, Australian Research Council Centre of Excellence for Environmental Decisions,

The Australian National University,

141 Linnaeus Way,

Canberra, ACT 2601, Australia

D.B. Lindenmayer (Corresponding author)

Email: david.lindenmayer@anu.edu.au,Tel: +612 61250654

Date of MS draft: 10 March 2017

Manuscript word count: 5733 (without appendices) 6429 (including appendices) 


\begin{abstract}
Context

The conversion of agricultural landscapes to tree plantations is a major form of landscape transformation worldwide, but its effects on biodiversity, particularly key population processes like reproductive success, are poorly understood.
\end{abstract}

\title{
Objectives
}

We compared bird breeding success between woodland remnants surrounded by maturing stands of plantation Radiata Pine and a matched set of woodland remnants in semi-cleared grazing land.

\section{Methods}

Our study was conducted in the Nanangroe region in south-eastern New South Wales, Australia. Using repeated field measurements, we quantified bird breeding success in 23 woodland remnants; 13 surrounded by Radiata Pine plantations and 10 on farms where remnants were surrounded by semi-cleared grazing land. We matched the attributes of native remnant patches between two types of matrix.

\section{Results}

We found that: (1) rates of nesting success of smaller-bodied birds in woodland remnants surrounded by grazing land were significantly higher than in woodland remnants surrounded by pine plantations; and (2) taxa with domed nests were more successful at nesting than species that constructed open cup/bowl nests in woodland remnants within farmlands.

\section{Conclusions}

Our findings suggest that bird breeding success in remnant woodland patches is significantly diminished as a result of the conversion of semi-cleared grazing land to pine plantations. 
Keywords: Agricultural landscape, breeding success, landscape change, matrix ecology, native vegetation cover, pine plantations.

\section{Introduction}

Landscape conversion is a major driver of species decline and local extinction (Bobo et al 2006; Davidai et al 2015; Dornelas et al 2014). The conversion of agricultural landscapes to tree plantations is a significant form of landscape transformation worldwide, and is part of meeting increasing demands for wood and paper products, as well as timber and carbon sequestration (FAO 2010; Hulvey et al 2013; Mortelliti and Lindenmayer 2015; Paquette and Messier 2010). Planted forests are predicted to cover 300 million hectares globally by 2020 (FAO 2010; Lindenmayer et al 2015b).

There is a wealth of literature on the response of biodiversity to agricultural landscape conversion to tree plantations (Felton et al 2010; Lindenmayer and Fischer 2006), particularly bird biota (Lindenmayer et al 2015a; Mortelliti and Lindenmayer 2015; Wilson et al 2014). The vast majority of these studies have documented patterns of species distribution and abundance but the key ecological processes underpinning these patterns remain largely unstudied. Breeding success is a critical ecological process influencing the likely persistence of species in natural and human-modified landscapes (Cruz-McDonnell and Wolf 2016; Gill 1985; With et al 2006). Yet, there have been remarkably few studies of bird breeding success in transforming landscapes (although see Zanette et al 2000). This, in turn, limits understanding of the factors governing species occurrence and patch occupancy in such landscapes.

Areas converted to tree plantations are often in fragmented landscapes that contain remnant patches of native vegetation (Driscoll et al 2013; Lindenmayer 2009). Some species occupying native vegetation patches may be susceptible to edge effects as well as changes in 
the surrounding matrix (Driscoll et al 2013) including impaired breeding performance (Hinsley et al 1999; Zanette et al 2000). For example, nest predation rates may differ in small patches due to increased edge effects (Lahti 2001; Newmark and Stanley 2011) as well as potential differences in landscape context (Lloyd et al 2005) such as the predator community occupying the matrix (DeGregorio et al 2014; Donovan et al 1997). Rates of nest parasitism are also influenced by both edge effects and landscape context (Howell et al 2007; Lloyd et al 2005). However, there have been few studies of matrix effects on breeding success of birds inhabiting plantation-dominated landscapes.

To close this knowledge gap, we conducted an empirical study of bird breeding success in patches of remnant native woodland surrounded by areas which, in the last two decades, have been undergoing transformation from semi-cleared grazing land to plantations of exotic Radiata Pine (Pinus radiata). We compared bird breeding success within woodland patches surrounded by maturing pine stands with a replicated set of woodland patches where the surrounding landscape was dominated by semi-cleared grazing farmlands. Specifically, we posed the following three key questions:

\section{Q1: Are there differences in rates of breeding success between woodland remnants} surrounded by pine plantations and woodland patches located in semi-cleared grazing paddocks? We postulated that bird breeding success would be higher in remnants surrounded by plantations than in remnants within farmlands. This prediction was based on likely differences in predator abundance and microclimatic conditions that would influence nesting success. First, bird data previously collected in our study area showed that the number of species of avian predators within farmlands was significantly higher than in plantations $\left(\chi_{1}^{2}=\right.$ 14.421 and $\mathrm{P}=0.001$ for $2009, \chi_{1}^{2}=15.109$ and $\mathrm{P}=0.001$ for 2011). Second, remnants surrounded by pine plantations would be characterized by more stable micro-environmental conditions than remnants in semi-cleared grazing environments. Such conditions include 
reduced wind speeds and less variation in temperature. Reproductive performance in birds may be promoted under such conditions (see DuRant et al 2013; Hepp and Kennamer 2012). In addition, the two kinds of woodland patches in our study differed markedly in landscape context (sensu Lindenmayer and Fischer 2006) and this will produce differences in edge contrast and edge effects, patterns of habitat connectivity, and other factors (Harper et al. 2005). Fragmentation theory and landscape ecology (matrix) theory suggest that differences in landscape context should have marked effects on biota, including reproductive success (see Driscoll et al 2013).

\section{Q2: Is there a relationship between bird breeding success and the amount of woody} vegetation cover in the landscape surrounding nests? We postulated that nests in areas surrounded by large amounts of native woody vegetation cover would be more successful than nests where the amount of surrounding native woody cover was limited. We based this prediction on previous work showing that larger areas of native eucalypt woodland provide a greater variety of food resources for birds than small areas of woodland (Zanette et al 2000).

\section{Q3: Is there a relationship between bird breeding success and life-history attributes or nest characteristics and do these relationships vary between woodland patches in} farmlands and plantations? Previous work has revealed that bird breeding success may be linked with life-history attributes such as nest type and nest height (Best and Stauffer 1980; Collias 1997; Colombelli-Négrel and Kleindorfer 2009; Noske et al 2008) although these relationships may vary between different ecosystems (e.g. Knutson et al 2004; Massaro et al 2013). We predicted that relationships between life history attributes and bird breeding success would be prominent as an earlier experiment in a neighbouring region found depressed levels of occurrence among open cup nesters in forest patches surrounded by recently harvested pines versus uncut pine stands (Lindenmayer et al 2009). 
Breeding success is a critical population process influencing the persistence of bird species in natural and human-dominated landscapes (Cruz-McDonnell and Wolf 2016; Gill 1985; With et al 2006). Therefore, our results will help inform effective strategies that attempt to integrate biodiversity conservation and wood production in plantation-dominated landscapes. This is particularly important as tree plantations occupy a large and rapidly increasing area worldwide (Lindenmayer et al 2015b).

\section{Methods}

\section{Study area}

Our study area covers approximately 56 square kilometres in the Nanangroe region, $20 \mathrm{~km}$ south-east of Jugiong in south-eastern New South Wales, Australia $\left(34^{\circ} 55^{\prime}-35^{\circ} 0\right.$ 'S, $148^{\circ} 25^{\prime}-$ $\left.148^{\circ} 35^{\prime} \mathrm{E}\right)$ (Figure 1). The Nanangroe region has a temperate climate with an annual rainfall of 900 to $1200 \mathrm{~mm}$ (Bureau of Meteorology 2015). The native vegetation cover in our study area is dominated by White Box (Eucalyptus albens), Yellow Box (E. melliodora), Red stringybark (E. macrorhyncha), Red Box (E. polyanthemos), and Blakely's Red Gum (E. blakelyi). Approximately $80 \%$ of the original native vegetation in the region has been cleared for grazing and cropping since European settlement (Lindenmayer et al 2008). The region has been undergoing extensive landscape transformation from semi-cleared grazing land to Radiata Pine plantations since the late 1990s. A major series of studies of the response of biodiversity to this landscape transformation has been taking place at 131 long-term monitoring sites first established in 1998 (Lindenmayer et al 2015a; Lindenmayer et al 2008; Lindenmayer et al 2001; Mortelliti et al 2015a; Mortelliti and Lindenmayer 2015; Mortelliti et al 2015b; Mortelliti et al 2014). The investigation reported here is the first to quantify patterns of bird breeding success at Nanangroe.

\#Figure 1 approximately here\# 


\section{Study sites}

For the study reported here on bird breeding success, we selected a subset of 23 woodland remnant sites from the 131 permanently-marked long-term monitoring sites at Nanangroe (for more details on the experimental design see Lindenmayer et al 2008; Lindenmayer et al 2001). The 23 sites comprised 13 woodland remnant sites surrounded by Radiata Pine plantations and 10 sites on farms where remnants were surrounded by semi-cleared grazing land.

We selected our sites to generally match the conditions of native remnant patches between two types of matrix. The average size of woodland remnants within farmlands and pine plantations was 5.2 hectares and 4.7 hectares, respectively $\left(\chi_{1}^{2}=0.026, \mathrm{P}=0.873\right)$. As riparian areas often support more biodiversity than elsewhere in a landscape (Jenkins et al 2013), we considered they may be superior breeding habitats (i.e. invertebrates as food and plants as habitats and food). Therefore, we selected the same number of riparian sites from each of the two types of matrix ( $n=3$ in either type of matrix).

Vegetation cover in the majority of sites was intact and in a relatively good condition, with a midstorey of Acacia spp, Kunzea spp and Eucalyptus saplings. The understorey was dominated by the exotic Blackberry (Rubus fruticosus). Other habitat structures, such as hollow-bearing trees and fallen logs, also were present at all of our sites. There was an intermediate level of livestock grazing in all woodland remnants (i.e. sites in both the plantations and the farmlands).

\section{Surveys for bird breeding success}

The breeding season for the majority of bird species in our study region is August to February (Beruldsen 2003). To maximise the chance of detecting breeding events, we searched for nests during the peak breeding season. Accordingly, we conducted surveys between September and December in 2012 and between October and December in 2013. Not 
all sites could be surveyed each year. In the farmland matrix, seven sites were surveyed in 2012 and ten in 2013. Corresponding figures for the pine matrix are eight and twelve sites. We located nests by following birds with nesting materials or searching likely places for breeding such as clumps of mistletoe and in tree hollows. For each nest, we recorded the GPS coordinates of the nest, bird species, and the species of plant on which a nest was built. We also measured nest height from ground level.

Every site was visited at least eight times to search for new nests during each survey season. We re-visited the sites every five to 14 days, with more frequent visits towards the end of survey seasons to determine the fate of nestlings. At every visit, we recorded nesting stage (building nest/incubating/nestlings/fledglings) until breeding success was determined. We defined the construction of nests as a 'Nesting Attempt' and the observation of at least one fledgling as 'Nesting Success'. We did not include nests in the analyses reported here for which we could not determine success.

We limited our nest searching efforts to an area within approximately 50 meters either side of a permanently marked 200 meter transect on each of the 23 sites in our study. However, we also recorded and monitored nests incidentally found outside of this searching area. Every time we visited each site, we spent approximately two hours searching for new nests and a further 20 minutes of observation time to document the status (e.g., active vs inactive) of each nest.

We recorded all nests detected in our repeated surveys. However, for subsequent data analyses we excluded nests constructed by water birds (most of which have a fundamentally different nesting niche relative to other bird species) and those of the migratory Whitebrowed Woodswallow (Artamus superciliosus). The White-browed Woodswallow is an irruptive, occasional migrant to our study area, and the large numbers that arrived to nest in 2013 would have skewed the results. 


\section{Definition of small versus large-bodied birds}

To calculate a median body size of birds occurring in the study region, we used data from previous field surveys over the past 16 years for all of the species in the Nanangroe region (Lindenmayer et al 2008; Lindenmayer et al 2001). We excluded water birds since they have very different breeding ecology relative to the remainder of the bird assemblage. Median body mass of all bird species in the study area was 48.25 grams, and we used this value to distinguish between small-bodied birds and large-bodied birds. For instance, we classified the Brown Treecreeper (Climacteris picumnus) and Rufous Songlark (Cincloramphus mathewsi) as small-bodied birds and the Magpie-lark (Grallina cyanoleuca) and Noisy Friarbird (Philemon corniculatus) as large-bodied birds (Appendix 1).

\section{Woody Vegetation Cover}

We used fine-scale satellite data on vegetation cover to calculate the amount of native woody vegetation cover (including scattered paddock trees) in radii of $50 \mathrm{~m}, 100 \mathrm{~m}, 200 \mathrm{~m}, 300 \mathrm{~m}$ and $500 \mathrm{~m}$ surrounding each nest. Our source data were the time series grids of Forest Extent and Change (version 9), produced by the Australian Government Department of Environment (National Carbon Accounting System, http://pandora.nla.gov.au/pan/102841/200907280000/www.climatechange.gov.au/ncas/reports/tech09.html). We used Landsat satellite imagery to discriminate between forest and non-forest cover at a grid resolution of $25 \mathrm{~m}$.

\section{Statistical Analyses}

We compared the number of nests per site $\mathrm{x}$ year combination in remnants surrounded by pine plantations with those within farmlands by fitting a generalised linear model (GLM) with a quasi-Poisson response and a logarithmic link function. In a similar way, we compared the effect of the surrounding matrix on quantities such as success rate by assuming that the number observed had a quasi-binomial distribution. For these models, we used approximate F-tests to assess significance. To assess the effect of variables measured for individual nests, 
body mass of bird, nest height, and nest type, we used logistic regression with a logit link function and assumed a Bernoulli distribution for the data. The response variable was breeding success $(0=$ Failed, $1=$ Success $)$. We used Wald statistics to quantify the significance of the potential predictors.

As part of preliminary analyses, we tested for the effects of phylogeny on differences in the bird breeding success among the two different kinds of remnants but found no evidence for such effects. We suggest that this result may have been in part because of the large range of bird families $(\mathrm{N}=23)$ that occurred in both kinds of remnants. We also tested for the effects of spatial dependence in nesting success; successful nests may have been more likely to have been near to other successful nests, but again found no evidence for such effects. Finally, we tested for differences in the number of nests and nesting success between riparian and non-riparian areas and found no evidence for any significant differences between such kinds of sites. We used GenStat 64-bit Release 18.1 to conduct all statistical analyses.

\section{Results}

We found a total of 175 nests (42 species) over the two breeding seasons. Of these, five nests were constructed by water birds (Appendix 1) and 12 were constructed by the White-browed Woodswallow were excluded from our study leaving 158 nests for subsequent data analyses. Of these 114 were in remnants surrounded by farmland ( 70 were small bodied bird species, 44 were large bodied species) and 44 were in remnants surrounded by plantation ( 24 were small bodied, 20 were large bodied).

\section{Relationships between breeding success and matrix types}

We detected an average of approximately three times more nests per site in remnants within farmlands than remnants surrounded by plantations $\left(\mathrm{F}_{1,35}=19.7, \mathrm{P}<0.001\right.$; Table 1$)$. The proportion of generalist (non-woodland dependent) avian predator nests in remnants 
surrounded by pine plantations was significantly higher $(31.8 \%)$ than that of remnants within farms $(7.0 \%)\left(\mathrm{F}_{1,35}=11.8, \mathrm{P}=0.002\right)$.

Of the 158 nests selected for analyses of breeding success, 97 nests ( 27 species) successfully produced at least one fledgling. Overall, we found no difference in the rate of nest success between remnants within farmlands (63.2\%) and remnants surrounded by

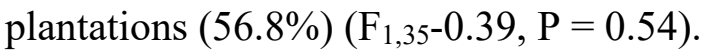

\section{Relationships between breeding success and vegetation cover}

We found no relationships between nest success and the amount of native woody vegetation cover in the surrounding landscape $(\mathrm{P}>0.05$ for any radii).

\section{Relationships between breeding success and bird life-history characteristics}

\section{Nest type}

We found a significant relationship between nesting success and nest type $\left(\chi_{1}^{2}=6.113, \mathrm{P}=\right.$ 0.013 ) for remnants surrounded by farmland. The predicted breeding success of open cup/bowl nesters was $54.8 \%$ and that of domed nesters was $84 \%$. By contrast, there was no difference in breeding success between two nest types in remnants surrounded by pine plantations (predicted success rate of cup/bowl nests $=0.333 \pm 0.192$, dome nests $=0.353 \pm$ $0.116)$.

\section{$\underline{\text { Body size }}$}

Larger species bred significantly more successfully than smaller species, irrespective of remnant type $\left(\chi_{1}^{2}=11.3, P<0.001\right.$; Figure 2$)$. For our study, examples of bird species with $7 \mathrm{~g}$ of average body mass included the Brown Thornbill (Acanthiza pusilla) and the Whitethroated Gerygone (Gerygone olivacea). Example species with larger body mass were the Noisy Friarbird (Philemon corniculatus, 100g body weight) and the Australian Raven (Corvus coronoides; $600 \mathrm{~g}$ body weight).

\#Figure 2 approximately here\# 


\section{Nest height}

We found no significant relationships between breeding success and nest height when all birds were considered $\left(\chi_{1}^{2}=2.1, P 0.142\right)$. We also failed to find a significant relationship with either remnant type $\left(\mathrm{X}^{2}=3.511, \mathrm{P}=0.061\right)$. However, birds smaller than the median body mass bred significantly more successfully at a lower nest height $\left(\chi_{1}^{2}=7.8, \mathrm{P}=0.005\right)$, whereas the success rate of species with larger body mass than the median weight was significantly greater at a higher locations $\left(\left(\chi_{1}^{2}=4.477, \mathrm{P}=0.034\right)\right.$. Predicted breeding success rates for smaller species were $64.7 \%$ and $43.4 \%$ for one metre and five metres of nest height, respectively.

\section{Discussion}

The area of tree plantations is expanding globally at a rate of 5 million hectares annually (FAO 2010; Guida-Johnson and Zuleta 2013; Watson et al 2014). Such kinds of landscape conversion can have significant impacts on biodiversity (Felton et al 2010) and can influence the abundance and occurrence of bird species in remaining native vegetation patches (Mortelliti et al 2014; Waltert et al 2004). Quantifying how bird breeding success changes in transforming plantation landscapes is a critical part of understanding the ecological processes affecting patterns of species abundance and distribution in these human-modified environments.

We found nest success rates of species smaller than the median body size in the Nanangroe region were significantly greater in remnants surrounded by farmlands than in remnants surrounded by stands of Radiata Pine plantation. There also were relationships between bird life-history characteristics and nest success, especially nest type. We discuss our key findings in the remainder of the paper and conclude with a summary of the conservation implications of this work. 


\section{Breeding success and matrix type}

At the outset of our study we predicted that breeding success in woodland remnants surrounded by stands of Radiata Pine plantation would be higher than woodland remnants within farmlands. However, we found strong evidence for the opposite effect for birds for which average body mass was smaller than a median size in the region. We also detected significantly more nests in remnants within farmlands than in remnants surrounded by stands of Radiata Pine plantation. Several factors may explain these results. First, densely spaced plantation trees may help conceal nests for some species thereby reducing the number of nests in adjacent woodlands remnants which are surrounded by stands of plantation Radiata Pine. Second, there may be differences in food availability between woodland remnants within the different matrices (Driscoll et al 2013). Invertebrates are a key prey item for many birds in our study area, particularly for smaller-bodied birds. Sweaney et al (2015) found fewer ground-active beetles and a reduced overall beetle diversity in remnants surrounded by plantations than remnants within farmlands. Reduced availability of food may result in nests/nestlings being left unattended for long periods, leaving them susceptible to predation and/or starvation (Rastogi et al 2006).

Differences in the abundance of avian predator nests may be a third factor explaining contrasts in breeding success between remnants within farmlands and remnants surrounded by stands of Radiata Pine plantation is. Our long-term field survey data from the Nanangroe region indicated that avian predators were more abundant on farms than plantations in both $2012\left(\chi_{1}^{2}=10.582, \mathrm{P}=0.0019\right)$ and $2013\left(\chi_{1}^{2}=12.709, \mathrm{P}=0.001\right)$. However, surprisingly, we found significantly more nests of avian predators, particularly ravens, in remnants surrounded by pine plantations than in woodland remnants on farms (Appendix 1). This suggests that the abundance of predators may not be directly related to the abundance of nests 
for some species of avian predators. The presence of nesting avian predators also may have discouraged other bird species from breeding.

Land surrounding woodland remnants (the matrix) could provide food resources and/or habitat for some bird species (Manning et al 2004). Some species may have perceived pine trees at the edges of woodland remnants as being relatively safe nesting sites (Chalfoun and Martin 2010; Dukas 2013), particularly small-bodied species such as the Grey Fantail (Rhipidura albiscapa) and various species of Thornbills (Acanthiza spp) (Appendix 2).

\section{Relationships between breeding success and vegetation cover}

At the outset of this study we predicted that nest success would be greater at those nests characterized by large areas of surrounding native woody vegetation cover as found in other environments around the world, including those in Europe (Mackenzie et al. 2014). However, we found no evidence of such effects and the reasons for the paucity of such effects remain unclear. The discrepancy between the results of this study and those of other investigations suggests that the effects of the amount of surrounding vegetation cover on bird breeding success is an area for further study, potentially involving greater field effort and more sites that we were able to examine.

\section{Relationships between breeding success and bird life history attributes}

We found that for woodland remnants on farms, birds with domed nests bred significantly more successfully than species with open cup/bowl nests. However, there were no relationships between nest type and breeding success in remnants surrounded by pine plantations. This suggests that different mechanisms may be driving nest success in woodland remnants with different surrounding matrices. Our results may be attributed to several factors. In remnant on farms, differences in nest success may be driven by climate and/or predation pressures. First, birds with domed nests may have been better able to survive the extreme temperatures which characterized the 2013 field season (Appendix 3) (Collias 1997). 
Conversely, some species of open cup/bowl nesters, such as the Willie Wagtail (Rhipidura leucophrys) and Flycatchers (Myiagra spp), nested in exposed places, such as on dead branches, where visually-cued avian predators could detect them (Gardner 1998). In remnants surrounded by pine plantations, limited availability of food (Sweaney et al 2015) may underpin the absence of relationships between nest type and breeding success. We acknowledge that the relatively small sample sizes in our study also may have led to a paucity of relationships between nest type and breeding success, although extensive field searching coupled with the considerable difficulty in finding and then repeatedly monitoring nests in our study precluded the inclusion of more nests.

We found that larger species of birds bred significantly more successfully than smaller birds. Larger species may be able to better defend their nests than smaller species (Remeš et al 2012). Ford (1999) found the Noisy Friarbird aggressively and successfully protected their conspicuous nests from avian predators. In our study, the Noisy Friarbird accounted for a large percentage of nests of larger species. Indeed, this species was characterised by a very high breeding success rate $(71.4 \%)$.

We found no significant relationships between breeding success and nest height either overall or within either of the types of woodland patches. However, the breeding success of smaller-bodied birds was negatively correlated with nest height and the opposite effect was identified for larger-bodied birds. In our study sites, the understorey was often comprised of thickets of the exotic Blackberry (Rubus fruiticosus). Although Blackberry is a weed of National Significance (Department of the Environment 2016), thickets of this invasive plant species appeared to be useful for breeding by smaller-bodied birds. In fact, we found many nests of small-bodied birds in Blackberry thickets (Appendix 1). It is common for exotic plant species to provide some resources for wildlife in human-modified landscapes (Chambers and Dickman 2002; Lampert et al. 2014). 


\section{Conclusions}

We detected an average of approximately three times more nests per site in remnants within farmlands than remnants surrounded by plantations. The proportion of generalist (nonwoodland dependent) avian predator nests in remnants surrounded by pine plantations was significantly higher than that of remnants within farms. In addition, taxa with domed nests were more successful at nesting than species that constructed open cup/bowl nests in woodland remnants within farmlands. Different mechanisms may be driving nest success in woodland remnants with different surrounding matrices. Resource limitations (e.g. invertebrate prey) and the abundance of avian predators may be factors underpinning reduced overall abundance of nests and relatively low levels of nesting success in woodland remnants surrounded by stands of plantation pine.

\section{Acknowledgements}

We thank Andrew Keating for access to his farms. We thank Damian Michael for his comments that improved earlier versions of the manuscript. Field work was approved by Animal Ethics Committee of The Australian National University (Approved Number: A2012/46) and also conducted under a NPWS Scientific Research Licence (SL100982). 
Table 1. Total number of nests and number of species that were detected and analysed for breeding success and number of nests of avian predators.

\begin{tabular}{lccc}
\hline & $\begin{array}{c}\text { Total number of } \\
\text { nests detected }\end{array}$ & $\begin{array}{c}\text { Number of nests } \\
\text { analysed for } \\
\text { breeding success }\end{array}$ & $\begin{array}{c}\text { Number of nests of } \\
\text { generalist avian } \\
\text { predators }\end{array}$ \\
\hline Remnants within & $131(32 \mathrm{spp})$ & $114(29 \mathrm{spp})$ & $8(2 \mathrm{spp})$ \\
farmlands & $44(21 \mathrm{spp})$ & $44(21 \mathrm{spp})$ & $15(6 \mathrm{spp})$ \\
Remnants within & & \\
plantations & & & \\
Total & $175(42 \mathrm{spp})$ & $158(39 \mathrm{spp})$ & $23(6 \mathrm{spp})$ \\
\hline
\end{tabular}


Figure 1. Sites where studies of bird breeding success were conducted. The squares show the location of remnant sites on farmlands and the circles indicate remnant sites within pine plantations.

Figure 2. Predicted breeding success rates (y-axis) plotted against body mass with approximate $95 \%$ confidence intervals. 
Figure 1

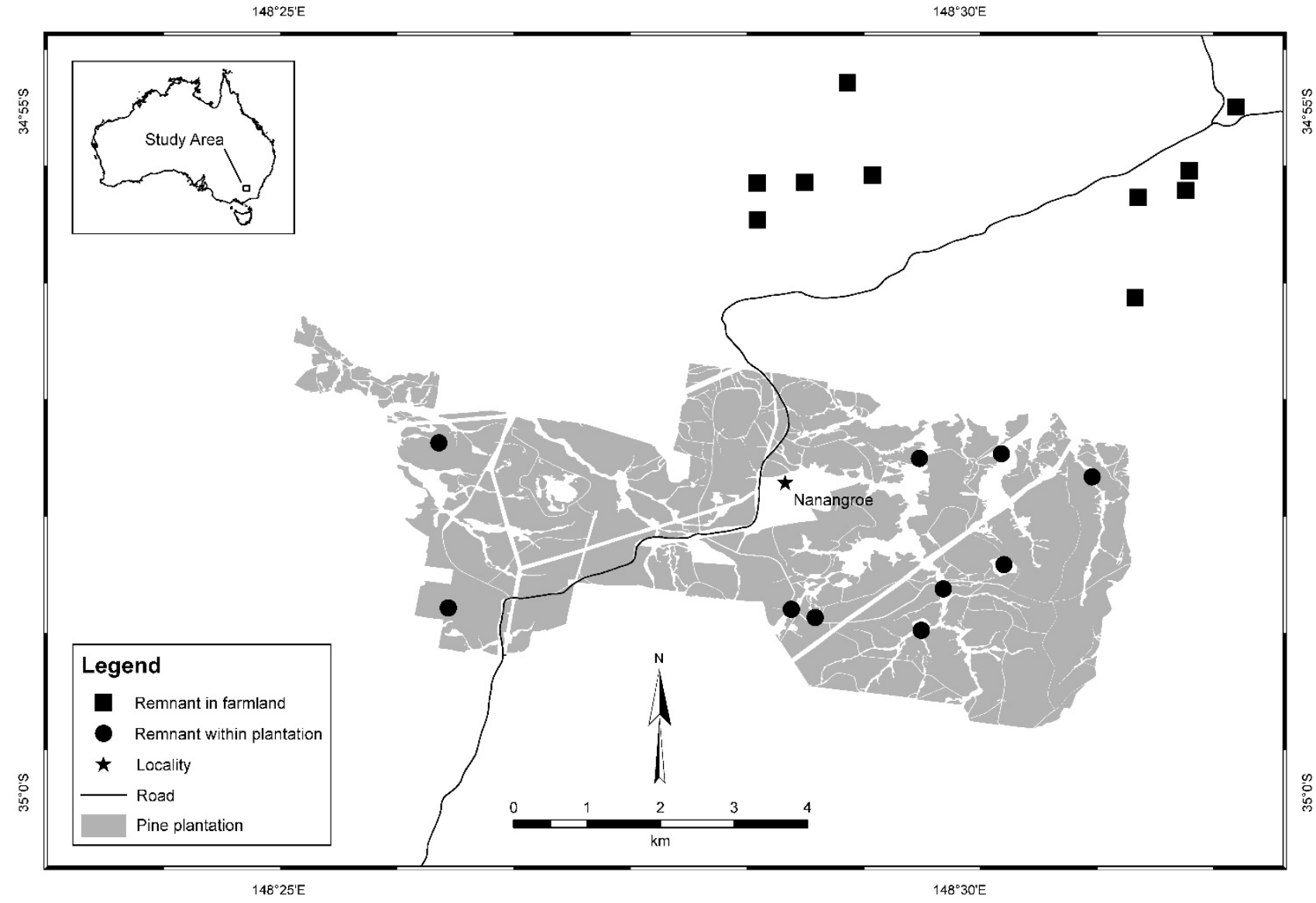


Figure 2

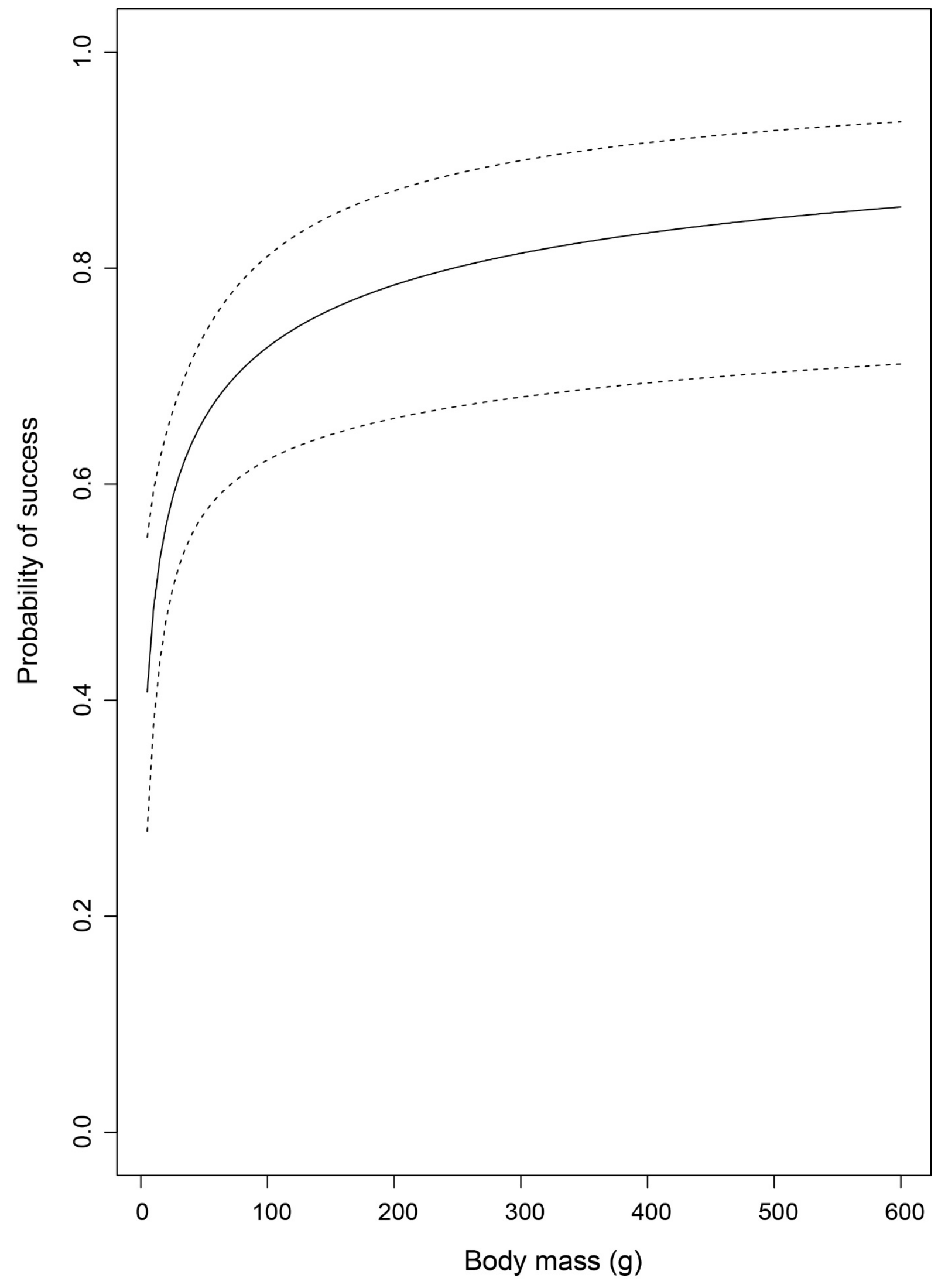




\section{References}

Beruldsen GR (2003) Australian birds: Their nests and eggs. G \& E Beruldsen, Kenmore Hills, Australia

Best LB, Stauffer F (1980) Factors affecting nesting success in riparian bird communities. The Condor 82:149

Bobo KS, Waltert M, Fermon H et al (2006) From forest to farmland: Butterfly diversity and habitat associations along a gradient of forest conversion in southwestern Cameroon. J Insect Conserv 10:29-42

Bureau of Meteorology 2015. Twelve-monthly rainfall totals for New South Wales/ACT, http://www.bom.gov.au/jsp/awap/rain/index.jsp? colour=colour\&time=latest\&step=0\&map=t otals\&period $=12$ month\&area $=$ ns. Australian Government

Chalfoun AD, Martin TE (2010) Facultative nest patch shifts in response to nest predation risk in the Brewer's sparrow: a "win-stay, lose-switch" strategy? Oecologia 163:885-892 Chambers LK, Dickman CR (2002) Habitat selection of the long-nosed bandicoot, Perameles nasuta (Mammalia, Peramelidae), in a patchy urban environment. Austral Ecol 27:334-342 Collias NE (1997) On the origin and evolution of nest building by passerine birds. The Condor 99:253-270

Colombelli-Négrel D, Kleindorfer S (2009) Nest height, nest concealment, and predator type predict nest predation in superb fairy-wrens (Malurus cyaneus). Ecol Res 24:921-928 Cruz-McDonnell KK, Wolf BO (2016) Rapid warming and drought negatively impact population size and reproductive dynamics of an avian predator in the arid southwest. Glob Change Biol 22:237-253

Davidai N, Westbrook JK, Lessard J-P et al (2015) The importance of natural habitats to Brazilian free-tailed bats in intensive agricultural landscapes in the Winter Garden region of Texas, United States. Biol Conserv 190:107-114 
DeGregorio BA, Weatherhead PJ, Sperry JH (2014) Power lines, roads, and avian nest survival: Effects on predator identity and predation intensity. Ecol Evol 4:1589-1600 Department of the Environment 2016. Weeds of National Significance: http://www.environment.gov.au/biodiversity/invasive/weeds/weeds/lists/wons.html. Department of the Environment, Canberra Donovan TM, Jones PW, Annand EM et al (1997) Variation in local-scale edge effects: Mechanisms and landscape context. Ecol 78:2064

Dornelas M, Gotelli NJ, McGill B et al (2014) Overlooked local biodiversity loss: Response. Science 344:1098-1099

Driscoll DA, Banks SC, Barton PS et al (2013) Conceptual domain of the matrix in fragmented landscapes. Trends Ecol Evol 28:605-613

Dukas R (2013) Effects of learning on evolution: robustness, innovation and speciation. Anim Behav 85:1023-1030

DuRant SE, Hopkins WA, Hepp GR et al (2013) Ecological, evolutionary, and conservation implications of incubation temperature-dependent phenotypes in birds. Biol Rev 88:499-509 FAO 2010. Global Forest Resources Assessment 2010: Main Report. Food and Agriculture Organisation, Rome

Felton A, Knight E, Wood J et al (2010) A meta-analysis of fauna and flora species richness and abundance in plantations and pasture lands. Biol Conserv 143:545-554 Ford HA (1999) Nest site selection and breeding success in large Australian honeyeaters: Are there benefits from being different? Emu 99:91-99

Gardner JL (1998) Experimental evidence for edge-related predation in a fragmented agricultural landscape. Aust J Ecol 23:311-321

Gill DE (1985) Interpreting breeding patterns from census data: A solution to the husting dilemma. Ecol 66:344-354 
Guida-Johnson B, Zuleta GA (2013) Land-use land-cover change and ecosystem loss in the Espinal ecoregion, Argentina. Agric, Ecosyst, Environ 181:31-40

Harper KA, Macdonald SE, Burton PJ, Chen JQ, Brosofske KD, Saunders SC, Euskirchen ES, Roberts D, Jaiteh MS, Esseen PA (2005) Edge influence on forest structure and composition in fragmented landscapes. Conserv Biol 19: 768-782.

Haslem A, Bennett AF (2011) Countryside vegetation provides supplementary habitat at the landscape scale for woodland birds in farm mosaics. Biodivers Conserv 20:2225-2242 Hepp GR, Kennamer RA (2012) Warm is better: Incubation temperature influences apparent survival and recruitment of wood ducks (Aix sponsa). PLoS ONE 7:e47777 Hinsley SA, Rothery P, Bellamy PE (1999) Influence of woodland area on breeding success in great tits Parus major and blue tits Parus caeruleus. J Avian Biol 30:271-281 Howell CA, Dijak WD, Thompson FR (2007) Landscape context and selection for forest edge by breeding Brown-headed Cowbirds. Landscape Ecol 22:273-284 Hulvey KB, Hobbs RJ, Standish RJ et al (2013) Benefits of tree mixes in carbon plantings. Nature Clim Change 3:869-874

Jenkins SR, Betts MG, Huso MM et al (2013) Habitat selection by juvenile Swainson's thrushes (Catharus ustulatus) in headwater riparian areas, Northwestern Oregon, USA. Forest Ecol Manage 305:88-95

Knutson MG, Niemi GJ, Newton WE et al (2004) Avian nest success in midwestern forests fragmented by agriculture. The Condor 106:116-130

Lahti DC (2001) The "edge effect on nest predation" hypothesis after twenty years. Biol Conserv 99:365-374

Lampert A, Hastings A, Grosholz ED, Jardine SL, Sanchirico JN (2014) Optimal approaches for balancing invasive species eradication and endangered species management. Science 344:1028-1031 
Lindenmayer D, Blanchard W, Tennant P et al (2015a) Richness is not all: How changes in avian functional diversity reflect major landscape modification caused by pine plantations.

Divers Distrib 21:836-847

Lindenmayer D, Messier C, Paquette A et al (2015b) Managing tree plantations as novel socioecological systems: Australian and North American perspectives. Can J Forest Res $45: 1427-1433$

Lindenmayer DB (2009) Large-scale landscape experiments. Lessons from Tumut. Cambridge University Press, Cambridge

Lindenmayer DB, Cunningham RB, MacGregor C et al (2008) Temporal changes in vertebrates during landscape transformation: A large-scale "natural experiment". Ecol Monogr 78:567-590

Lindenmayer DB, Cunningham RB, MacGregor C et al (2001) A prospective longitudinal study of landscape matrix effects on fauna in woodland remnants: Experimental design and baseline data. Biol Conserv 101:157-169

Lindenmayer DB, Fischer J (2006) Habitat fragmentation and landscape change. Island Press, Washington, DC

Lindenmayer DB, Wood JT, Cunningham RB et al (2009) Experimental evidence of the effects of a changed matrix on conserving biodiversity within patches of native forest in an industrial plantation landscape. Landscape Ecol 24:1091-1103 Lloyd P, Martin TE, Redmond RL et al (2005) Linking demographic effects of habitat fragmentation across landscapes to continental source-sink dynamics. Ecol Appl 15:15041514

Mackenzie JA, Hinsley SA, and Harrison NM (2014) Parid foraging choices in urban habitat and their consequences for fitness. Ibis 156:591-605. 
Manning AD, Lindenmayer DB, Barry SC (2004) The conservation implications of bird reproduction in the agricultural "matrix": A case study of the vulnerable superb parrot of south-eastern Australia. Biol Conserv 120:363-374

Massaro M, Stanbury M, Briskie JV (2013) Nest site selection by the endangered black robin increases vulnerability to predation by an invasive bird. Anim Conserv 16:404-411

Mortelliti A, Crane M, Okada S et al (2015a) Marsupial response to matrix conversion:

Results of a large-scale long-term 'natural experiment' in Australia. Biol Conserv 191:60-66

Mortelliti A, Lindenmayer DB (2015) Effects of landscape transformation on bird colonization and extinction patterns in a large-scale, long-term natural experiment. Conserv Biol 29:1314-1326

Mortelliti A, Michael DR, Lindenmayer DB (2015b) Contrasting effects of pine plantations on two skinks: Results from a large-scale 'natural experiment' in Australia. Anim Conserv $18: 433-441$

Mortelliti A, Westgate MJ, Lindenmayer DB (2014) Experimental evaluation shows limited influence of pine plantations on the connectivity of highly fragmented bird populations. $\mathrm{J}$ Appl Ecol 51:1179-1187

Newmark WD, Stanley TR (2011) Habitat fragmentation reduces nest survival in an Afrotropical bird community in a biodiversity hotspot. Proc Natl Acad Sci USA 108:1148811493

Noske RA, Fischer S, Brook BW (2008) Artificial nest predation rates vary among habitats in the Australian monsoon tropics. Ecol Res 23:519-527

Paquette A, Messier C (2010) The role of plantations in managing the world's forests in the Anthropocene. Front Ecol Environ 8:27-34

Rastogi DA, Zanette L, Clinchy M (2006) Food availability affects diurnal nest predation and adult antipredator behaviour in song sparrows, Melospiza melodia. Anim Behav 72:933-940 
Remeš V, Matysioková B, Cockburn A (2012) Long-term and large-scale analyses of nest predation patterns in Australian songbirds and a global comparison of nest predation rates. $\mathrm{J}$ Avian Biol 43:435-444

Sweaney N, Driscoll DA, Lindenmayer DB et al (2015) Plantations, not farmlands, cause biotic homogenisation of ground-active beetles in south-eastern Australia. Biol Conserv $186: 1-11$

Waltert M, Mardiastuti ANI, MÜHlenberg M (2004) Effects of land use on bird species richness in Sulawesi, Indonesia. Conserv Biol 18:1339-1346

Watson SJ, Luck GW, Spooner PG et al (2014) Land-use change: incorporating the frequency, sequence, time span, and magnitude of changes into ecological research. Front Ecol Environ 12:241-249

Wilson JD, Anderson R, Bailey S et al (2014) Modelling edge effects of mature forest plantations on peatland waders informs landscape-scale conservation. J Appl Ecol 51:204213

With KA, Schrott GR, King AW (2006) The implications of metalandscape connectivity for population viability in migratory songbirds. Landscale Ecol 21:157-167

Zanette L, Doyle P, Tremont SM (2000) Food shortage in small fragments: Evidence from an area-sensitive passerine. Ecol 81:1654-1666 


\section{Appendices}

Appendix 1. Species of nests that we found with average body mass and nest type.

* indicates raptors and generalist avian predators. \# shows woodland dependant avian predators.

Number of Number of Avg Body Nest Type

Nests Nests Mass (g)

in

in

Remnants Remnants

surrounded surrounded

by by Pine

Farmland Plantations

\begin{tabular}{llllll}
\hline Australasian Grebe & Tachybaptus novaehollandiae & 3 & 0 & 219 & Waterweed Plat \\
Australian Magpie* & Cracticus tibicen & 6 & 6 & 296 & Stick Platform \\
Australian Raven* & Corvus coronoides & 0 & 4 & 638 & Stick Platform \\
Black-faced Cuckoo-shrike & Coracina novaehollandiae & 2 & 0 & 118 & Cup/Bowl \\
Brown Thornbill & Acanthiza pusilla & 0 & 2 & 7 & Dome \\
Brown Treecreeper & Climacteris picumnus & 2 & 0 & 32 & Hollow/Burrow \\
Buff-rumped Thornbill & Acanthiza reguloides & 4 & 3 & 8 & Dome \\
Collared Sparrowhawk* & Accipiter cirrocephalus & 0 & 1 & 172 & Stick Platform \\
Crimson Rosella & Platycercus elegans & 0 & 2 & 133 & Hollow/Burrow \\
Dusky Woodswallow & Artamus cyanopterus & 2 & 0 & 35 & Cup/Bowl \\
Flame Robin & Petroica phoenicea & 0 & 2 & 13 & Cup/Bowl \\
Grey Butcherbird* & Cracticus torquatus & 0 & 1 & 88 & Stick Platform \\
Grey Fantail & Rhipidura albiscapa & 4 & 1 & 8 & Cup/Bowl \\
Jacky Winter & Microeca fascinans & 2 & 0 & 16 & Cup/Bowl \\
Laughing Kookabura* & Dacelo novaeguineae & 0 & 1 & 339 & Hollow/Burrow \\
Leaden Flycatcher & Myiagra rubecula & 5 & 0 & 14 & Cup/Bowl
\end{tabular}




\begin{tabular}{|c|c|c|c|c|c|}
\hline Magpie-lark & Grallina cyanoleuca & 4 & 0 & 87 & Cup/Bowl \\
\hline Mistletoebird & Dicaeum hirundinaceum & 3 & 0 & 9 & Dome \\
\hline Noisy Fraiarbird\# & Philemon corniculatus & 27 & 1 & 101 & Cup/Bowl \\
\hline Pied Currawong* & Strepera graculina & 2 & 2 & 332 & Stick Platform \\
\hline Rainbow Bee-eater & Merops ornatus & 1 & 0 & 27 & Hollow/Burrow \\
\hline Red Wattlebird & Anthochaera carunculata & 1 & 2 & 114 & Cup/Bowl \\
\hline Restless Flycatcher & Myiagra inquieta & 2 & 0 & 21 & Cup/Bowl \\
\hline Rufous Songlark & Cincloramphus mathewsi & 2 & 0 & 29 & Cup/Bowl \\
\hline Rufous Whistler & Pachycephala rufiventris & 1 & 0 & 25 & Cup/Bowl \\
\hline Sacred Kingfisher & Todiramphus sanctus & 0 & 1 & 43 & Hollow/Burrow \\
\hline Silvereye & Zosterops lateralis & 2 & 0 & 12 & Cup/Bowl \\
\hline Spotted Pardalote & Pardalotus punctatus & 1 & 0 & 9 & Hollow/Burrow \\
\hline Striated Pardalote & Pardalotus striatus & 2 & 2 & 12 & Hollow/Burrow \\
\hline Superb Fairy-wren & Malurus cyaneus & 5 & 4 & 10 & Dome \\
\hline Weebill & Smicrornis brevirostris & 0 & 1 & 6 & Dome \\
\hline Western Gerygone & Gerygone fusca & 1 & 0 & 7 & Dome \\
\hline White-browed Scrubwren & Sericornis frontalis & 0 & 1 & 13 & Dome \\
\hline White-browed Woodswallow & Artamus superciliosus & 12 & 0 & 36 & Cup/Bowl \\
\hline White-faced Heron & Egretta novaehollandiae & 2 & 0 & 585 & Stick Platform \\
\hline White-throated Gerygone & Gerygone olivacea & 6 & 5 & 7 & Dome \\
\hline White-throated treecreeper & Cormobates leucophaea & 2 & 1 & 23 & Hollow/Burrow \\
\hline White-winged Chough\# & Corcorax melanorhamphos & 2 & 0 & 368 & Cup/Bowl \\
\hline White-winged Triller & Lalage sueurii & 5 & 0 & 25 & Cup/Bowl \\
\hline Willie Wagtail & Rhipidura leucophrys & 11 & 0 & 21 & Cup/Bowl \\
\hline Yellow-faced Honeyeater & Caligavis chrysops & 1 & 0 & 17 & Cup/Bowl \\
\hline Yellow-rumped Thornbill & Acanthiza chrysorrhoa & 6 & 1 & 10 & Dome \\
\hline
\end{tabular}


Appendix 2. Species showing evidence of nesting in pine trees

\begin{tabular}{l|l|c|l}
\hline Common Name & Scientific Name & Abundance & Breeding stage/Behaviours \\
\hline Brown Thornbill & Acanthiza pusilla & 1 & Fledglings \\
Brown Thornbill & Acanthiza pusilla & 2 & Carrying food into pine stands \\
Buff-rumped Thornbill & Acanthiza reguloides & 1 & Carrying food into pine stands \\
Buff-rumped Thornbill & Acanthiza reguloides & 1 & Carrying nesting materials into pine stands \\
Eastern Yellow Robin & Eopsaltria australis & 1 & Incubating on nest in pine tree \\
Grey Fantail & Rhipidura albiscapa & 1 & Fledglings \\
Grey Fantail & Rhipidura albiscapa & 1 & Incubating on nest in pine tree \\
Grey Fantail & Rhipidura albiscapa & 3 & Carrying nesting materials into pine stands \\
Silvereye & Zosterops lateralis & 1 & Carrying nesting materials into pine stands \\
White-browed Scrubwren & Sericornis frontalis & 1 & Feeding nestlings \\
White-browed Scrubwren & Sericornis frontalis & 1 & Nestlings \\
Yellow-faced Honeyeater & Caligavis chrysops & 1 & Feeding fledgelings \\
Yellow-faced Honeyeater & Caligavis chrysops & 1 & Carrying nesting materials into pine stands \\
Yellow-rumped Thornbill & Acanthiza chrysorrhoa & 1 & Fledglings \\
\hline
\end{tabular}


Appendix 3. Figure derived from Bureau of Meteorology website, showing the highest temperature of a month in 2013 at Burrinjuck Dam weather station, compared with historical highest temperature of a month from 1965 to 2016.

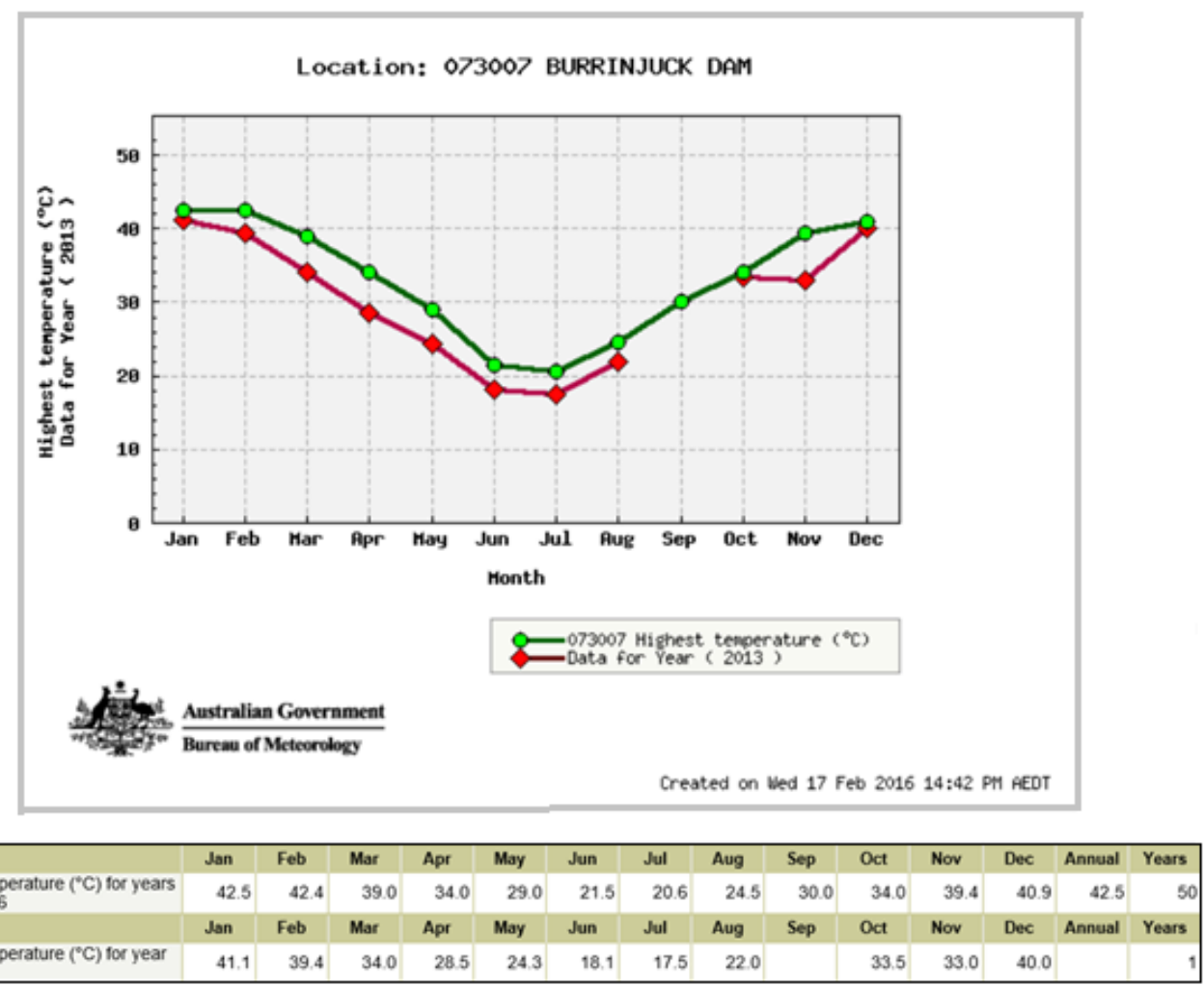

\begin{tabular}{|c|c|c|c|c|c|c|c|c|c|c|c|c|c|c|}
\hline Statistics & Jan & Feb & Mar & Apr & May & Jun & Jul & Aug & Sep & Oct & Nov & Dec & Annual & Years \\
\hline $\begin{array}{l}\text { Highest temperature ("C) for years } \\
1965 \text { to } 2016\end{array}$ & 42.5 & 42.4 & 39.0 & 34.0 & 29.0 & 21.5 & 20.6 & 24.5 & 30.0 & 34.0 & 39.4 & 40.9 & 42.5 & so \\
\hline Statistics & Jan & Feb & Mar & Apr & May & Jun & Jul & Aug & Sep & Oct & Nov & Dec & Annual & Years \\
\hline $\begin{array}{l}\left.\text { Highest temperature ( }{ }^{\circ} \mathrm{C}\right) \text { for year } \\
2013\end{array}$ & 41.1 & 39.4 & 34.0 & 28.5 & 24.3 & 18.1 & 17.5 & 22.0 & & 33.5 & 33.0 & 40.0 & & 1] \\
\hline
\end{tabular}

